\title{
Imigração Haitiana em Manaus Presença da Pastoral do Migrante
}

\author{
Pe. Gelmino A. Costa * \\ Desde 1993, pela voz de Caetano Veloso, \\ ouvimos: \\ "Pense no Haiti, reze pelo Haiti \\ O Haiti é aqui \\ O Haiti não é aqui."
}

A partir de 2010, a sociedade brasileira começou a ouvir: "Os haitianos estão aqui." Nós, da Pastoral do Migrante, não ouvimos dizer, nós os acolhemos, apertamos a mão a todos no momento da chegada. Por isso, neste simples comunicado/testemunho, descreveremos, rapidamente, o processo de chegada dos imigrantes haitianos em Manaus, bem como a atitude de acolhida por parte da Igreja Católica e da sociedade civil.

\section{Os imigrantes haitianos em Manaus}

A emigração haitiana não é um fato novo. Há muitos anos eles estão em países como os Estados Unidos, Canadá, França, República Dominicana e outros, impulsionados por fatores de ordem econômica, social e política. Além disso, o país foi seguidamente castigado por catástrofes 'naturais': enchentes, tufões e, há pouco tempo, pelo terremoto que arrasou a capital, Porto Príncipe. Se, de um lado, a emigração não é novidade, fato novo é a chegada de haitianos ao Brasil

* Pe. Gelmino A. Costa é Missionário Scalabriniano e Agente da Pastoral do Migrante em Manaus. 
e, principalmente, a Manaus. Se a situação do Haiti já era difícil, o terremoto veio complicar em muito a vida do seu povo. Além da perda de vidas humanas, desapareceu o centro nevrálgico e mais dinâmico do país. Fome, doenças e desemprego se fizeram mais fortes. A própria ajuda internacional chegou e não chegou, ajudou, mas não resolveu.

É evidente que diante dessa situação toda, muita gente viu na emigração uma saída. Emigrar para buscar um futuro melhor e angariar recursos para ajudar os familiares e parentes que continuariam no Haiti. Muitos recolheram recursos para financiar a viagem junto aos familiares, junto a amigos migrantes que se encontram em outros países, ou vendendo pequenas propriedades. Mas ir para onde? O sonho era a América do Norte e a Europa, mas as portas estavam fechadas. Os Vistos não eram liberados. Teriam, então, que procurar países que não exigissem o Visto e, ao invés de olhar para o Norte, olhar para o Sul. Os primeiros buscaram o Equador, sem, porém, definir o seu destino. Alguns que haviam deixado o Haiti antes do terremoto chegaram a ficar diversos meses no Equador, mas as condições de trabalho e os salários não encorajavam a permanência. O Brasil foi visto como uma alternativa, primeiro, por ser o país com a economia mais dinâmica da América do Sul e, em segundo lugar, pela existência, entre os haitianos, de uma simpatia em relação ao Brasil, fomentada pelas declarações do governo brasileiro que prometera acolher bem os que aqui chegassem.

Por isso, no início de 2010, chegaram até a fronteira brasileira os primeiros que, deixando o Equador, foram para Lima, no Peru, onde embarcaram em outro avião rumo a Iquitos (Peru), e de lá tomaram o barco para Tabatinga (Brasil). A chegada desses coincidiu com o terremoto no Haiti. Era um momento de comoção nacional e mundial. O Brasil não tinha como impedir a entrada dos imigrantes. Falava-se de refúgio por catástrofes naturais, refúgio humanitário. $\mathrm{O}$ fato é que a Polícia Federal concedeu o Protocolo como solicitantes de refúgio, acompanhado por uma declaração pessoal emitida pelo CONARE.

Os que chegaram a Manaus entre fevereiro e junho de 2010, na verdade não permaneceram em Manaus, seguiram viagem, muitos em direção à Guiana Francesa. Até julho de 2010, a Pastoral do Migrante da Arquidiocese havia acolhido 140 pessoas e, até o final do mesmo ano, 380. Nos primeiros seis meses de 2011 chegaram a Manaus em torno de mil haitianos e, a quase totalidade aqui se estabeleceu. A grande maioria é composta por homens, com idade entre 25 e 35 anos.

\section{Ensaios de solidariedade}

Os imigrantes haitianos chegam a Manaus com uma história de viagem de até três meses, nunca inferior a um mês. Um verdadeiro caminho do Calvário. Uma história marcada pela angústia e sofrimento, pela privação e fome, de noites mal dormidas em minúsculos e lotados 'alojamentos'. Chegam a Manaus extenuados e, a maioria, sem um centavo no bolso. 
Inicialmente, parte dos imigrantes foi acolhida na casa do migrante do Estado, por onde passaram, em 2010, noventa e oito haitianos e, outra parte, numa casa de acolhida animada pelas Irmãs Scalabrinianas, mas que não comportava mais de quinze pessoas. No mês de agosto, os Religiosos Scalabrinianos abriram a casa Scalabrini, na paróquia de São Geraldo, com capacidade para doze pessoas, mas poucos dias depois da abertura já abrigava vinte imigrantes haitianos e colombianos. Em seguida, foram alugadas algumas casinhas e um casarão, sendo que este chegou a abrigar trinta e nove pessoas. Até aí a acolhida corria por conta dos religiosos e religiosas Scalabrinianos/as, recebendo algumas ajudas do Instituto Migrações e Direitos Humanos de Brasília. Em janeiro deste ano teve início uma nova etapa. Os imigrantes continuavam chegando. Foi feito o primeiro apelo à paróquia de São Raimundo e ao seu pároco, os quais abriram as portas de um grande salão equipado de cozinha e banheiros que chegou a acolher, no momento de pico, noventa imigrantes. Dali pra frente, o número dos que chegavam continuou crescendo. Só no dia 4 de março chegaram sessenta e oito haitianos. À medida que o número de imigrantes ia crescendo, cresciam também os gestos de solidariedade das comunidades católicas. Uma Ordem religiosa abriu a sua casa de retiros. Diversas paróquias criaram centros de acolhida, outras pagaram o valor de casas que eram alugadas e, outras ainda, ofereceram ajudas de todo tipo. A paróquia de São Geraldo transformou-se no ponto de chegada dos haitianos. A totalidade deles passou pela Pastoral do Migrante e encontrou em seus agentes e suas casas o seu primeiro ponto de acolhida. Mais de mil, só neste ano. Hoje, início de julho, estamos com 280 haitianos albergados em doze casas. Os outros conseguiram, em pequenos grupos, alugar casinhas muito humildes, mas muitos ainda buscam na pastoral ajuda para a alimentação. Isso porque os aluguéis são caros, o custo de vida é elevado, os salários são baixos e a maior fatia do que eles ganham remetem para os familiares que ficaram no Haiti.

Outro trabalho importante que os agentes da pastoral do migrante realizam é a ajuda para encontrar o primeiro trabalho. As casas de acolhida e, sobretudo, a paróquia de São Geraldo tornaram-se 'praças' de oferta de trabalho, com a chegada de empregadores da construção civil, da área de serviços gerais, de restaurantes, hotelaria e outros.

A grande maioria dos haitianos, de posse do CPF e da Carteira de Trabalho, consegue serviço nos primeiros dez dias. Percebe-se, claramente, que Manaus carece de mão de obra em setores em que os salários são mais baixos e os serviços mais pesados. Mais difícil é a ocupação para as mulheres, pois poucas ofertas aparecem fora do trabalho doméstico.

As comunidades católicas são as principais fontes de oferta de alimentos. Mas não podemos esquecer que o povo manauara foi, e continua sendo, muito sensível à causa dos haitianos. Houve campanhas nas escolas, junto a pequenos empresários e através dos meios de comunicação. Podemos afirmar que nunca faltou o essencial: feijão, arroz, macarrão, café, açúcar, óleo. A Pastoral do Migrante já recebeu e distribuiu cerca de sessenta toneladas de alimentos. A 
Secretaria Social de Assistência Social doou um número considerável de colchões, algumas cestas básicas e outros alimentos perecíveis.

Junto à alimentação, houve a doação de roupas, colchões, camas, fogões, panelas, ventiladores, enxovais para criancinhas - já nasceram em Manaus sete brasileiros, filhos de haitianos.

Outra expressão de solidariedade diz relação ao ensino da língua portuguesa, levado em frente, num primeiro momento, por voluntários da Pastoral do Migrante e, posteriormente, pela SEDUC - Secretaria Estadual de Educação e CETAM - Centro de Educação Tecnológica do Amazonas. Disponibilizaram professores e material didático e ministraram as aulas nos locais onde estão as casas de acolhida. O SENAI ofereceu e está oferecendo cursos profissionalizantes. O SENAC ofereceu um curso no setor da construção civil. A Superintendência do Trabalho apressou a distribuição das Carteiras de Trabalho.

Resumindo, coube à Igreja Católica ser a promotora da solidariedade e da acolhida dos imigrantes haitianos, mas coube ao povo de Manaus multiplicar os gestos de solidariedade. A sociedade em geral acolheu muito bem os haitianos, estes se integram rapidamente com a vizinhança onde moram ou com os companheiros de trabalho. Evidentemente, do outro lado, há os que reclamam silenciosamente e também os de mau humor, como é o caso de alguns políticos que afirmaram: "por que trazer mais pobres numa cidade onde há pobres de sobra?!"; "eles vão ocupar os nossos postos de trabalho!"; "eles vão trazer doenças!". Além de disparates contra a Igreja Católica, dizendo ser ela a que está trazendo os haitianos para Manaus. São pessoas de ideias curtas e mesquinhas, que só veem o migrante como um número, como um problema, mas que nunca se aproximaram dele para escutar a sua história, a sua alma, o seu sofrimento, os seus sonhos, o porquê ele deixou a sua pátria, o porquê chegou a Manaus. Então, essas pessoas armam o tribunal, se arvoram em juízes e condenam. Carecem de humanidade e de espírito cristão.

\section{Olhando para frente}

Olhando para frente parece que a vinda de haitianos não está chegando ao fim. É uma coisa lógica, pois enquanto persistirem as causas da emigração, haverá emigração. Ela pode ser melhor organizada? Claro que sim! O Brasil tem possibilidade de acolher mais haitianos? Claro que tem! O que o Brasil precisa é estabelecer uma verdadeira política migratória. Em primeiro lugar, com todas as forças da ONU, apoiar iniciativas de reconstrução do Haiti, tentando dar esperança para a maioria que não quer deixar o país, em segundo lugar, garantir um número de Vistos - a serem dados no Haiti - para os que desejarem vir ao Brasil. Desta maneira, os emigrantes poderiam chegar em poucas horas ao Brasil e serem distribuídos em muitas localidades; eles chegariam com algum dinheiro no bolso e sem passar pelo 'inferno' da atual rota, algumas vezes ficando à mercê dos 'traficantes de carne humana', como já dizia, no final do século XIX, o BemAventurado João Batista Scalabrini, pai e apóstolo dos migrantes. 
Se afirmamos que queremos acolher bem os haitianos - até mesmo oferecendo com muita rapidez a Residência permanente - vamos acolhê-los pela porta da frente e não pela dos fundos. Precisamos implementar políticas e iniciativas de inserção. $O$ povo brasileiro é hospitaleiro, demos as explicações para ele e não façamos as coisas às ocultas, por Tabatinga, que a grande maioria nem sabe que existe ou onde se encontra. Não deixemos a nossa sociedade vítima das tomadas de posições nazistas, alarmistas e xenófobas dos que sugerem, como única saída, que se encoste um avião da FAB em Tabatinga e que se deportem todos para o Haiti.

A experiência dos que atuam com os haitianos em Manaus - religiosos e religiosas, padres e leigos voluntários, enfim, toda a equipe da Pastoral do Migrante - em contato com a comunidade manauara, aponta para a acolhida, a solidariedade e a hospitalidade; aponta para o abraço entre os povos; aponta que a vida é mais importante que o passaporte e que todos têm o direito de viver no planeta Terra. É preciso encurtar as distâncias entre os povos, globalizar a vida e os povos, e não só o dinheiro; como se costuma dizer: "o que nos une é bem maior do que aquilo que nos separa".

Por último, para nós cristãos, de qualquer denominação, e que temos a Bíblia como mestra e guia, deixemo-nos orientar por ela, que nos diz: "Quando um imigrante habitar com vocês no país, não o oprimam. O imigrante será para vocês um concidadão: você o amará como a si mesmo, porque vocês foram imigrantes na terra do Egito" (Lv 19, 33-34); ou, como o próprio Jesus afirma: "Eu era estrangeiro e você me acolheu" (Mt 25, 35). 